\title{
Hautpflege
}

\section{Zuverlässiger Schutz bei Inkontinenz}

» Bei Inkontinenz oder auch im Alter ist die Haut starken Beanspruchungen ausgesetzt und benötigt eine spezielle Pflege. Die Hautschutzprodukte der Pflegeserie Menalind ${ }^{\circledR}$ professional protect sind auf die besonderen Bedürfnisse reifer oder belasteter Haut insbesondere bei Patienten mit Inkontinenz abgestimmt. Die Serie besteht aus einer transparen- ten Hautschutzcreme, einer Hautschutzcreme, einem Hautprotektor und einem Öl-Hautschutzspray. An Stellen, die aggressiven Substanzen wie Urin und Stuhl ausgesetzt sind, kann die intensiv schützende und transparente Hautschutzcreme dünn aufgetragen werden. Der leichte Schaum des Schaumsprays Menalind ${ }^{\circledR}$ professional Hautprotector zieht besonders schnell ein und bildet eine transparente Schutzschicht, die die Haut trotzdem noch atmen lässt. Gleichzeitig schränkt das Schaumspray - genau wie die transparente Hautschutzcreme - die Saugleistung von Inkontinenzprodukten nicht ein.

\section{www.hartmann.de}

\section{Sicher liegen}

\section{Innovative Konzepte rund ums Bett}

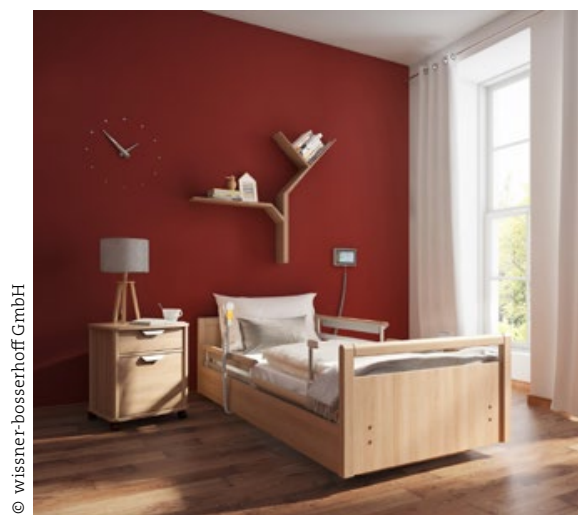

» Pflegebetten sollten Wohnlichkeit, Komfort und vor allem Multifunktionalität miteinander verbinden. Die Menschen in Pflegeeinrichtungen sol- len sich darin wohlfühlen. Doch gleichzeitig muss die Versorgung von bewegungseingeschränkten Menschen sichergestellt sein. Mit den Niedrigpflegebetten aus der sentida Reihe ist wissner-bosserhoff die konsequente und kompromisslose Umsetzung einer zeitgemäßen Pflege gelungen. Insgesamt sechs verschiedene Modelle stehen dem Kunden aus dieser Serie zur Auswahl.

Bettlägerige Menschen haben ein erwiesenermaßen erhöhtes Dekubitusrisiko. Ist das Druckgeschwür erst mal da, ist es eine große Belastung für die Pflegebedürftigen. Damit ein Dekubitus gar nicht erst entsteht, müssen vorbeugende Maßnahmen ergriffen werden. Bei allen seinen Pflegebetten setzt wissner-bosserhoff daher auf die soge- nannte BiNetic-Liegefläche. Die ergonomische Aufteilung dieser Liegefläche trägt zur Vermeidung von Druckbelastungen und damit zur Dekubitusreduzierung bei. Die Maße der 4-geteilten Liegefläche von Wissner-Bosserhoff Pflegebetten orientieren sich dabei an den Erkenntnissen der Anthropometrie, das heißt an der durchschnittlichen Körpergröße eines Menschen. Der sogenannte doppelte Rückzug ist Bestandteil der BiNeticLiegefläche. Dabei wird nicht nur die Rückenlehne, sondern auch die Beinlehne vom Sitzteil weg bewegt, so dass sich die Fläche vergrößert und Druckbelastungen deutlich reduziert werden.

\section{www.wi-bo.com}

\section{Übelkeit und Völlegefühl}

\section{Natürliche Hilfe bei Verdauungsstörungen}

» Bewegungsarmut führt zu vielen funktionellen Verdauungsstörungen. Die natürlichen Amara-Tropfen von Weleda sind eine Komposition aus Heilpflanzen, deren Bitterstoffe vor allem im oberen Verdauungstrakt eingreifen. Sie fördern die Verdauung, indem sie die Magensaftbildung, Galletätigkeit, die Sekretion von Bauchspeichel und die Magen-Darm-Bewegungen anregen. Hilfreich sind Amara-Tropfen vor allem bei Appetitlosigkeit, Völlegefühl, Übelkeit und Verdauungsschwäche. Sind die rhythmischen Abläufe im Magen-Darm-
Trakt gestört, so treten Symptome wie Sodbrennen, Völlegefühl, Blähungen, Durchfall und/oder Verstopfung auf. Hier können dann die Digestodoron ${ }^{\circledR}$ Dilution Tropfen helfen. Sie regen die rhythmischen Abläufe im Verdauungstrakt nachhaltig an und stellen bei längerfristiger Einnahme das rhythmische Gleichgewicht wieder her. Sie regulieren so die Verdauungstätigkeit und sind dafür geeignet, die allgemeine Neigung zu Magen-DarmProblemen zu verringern.

www.weleda.de

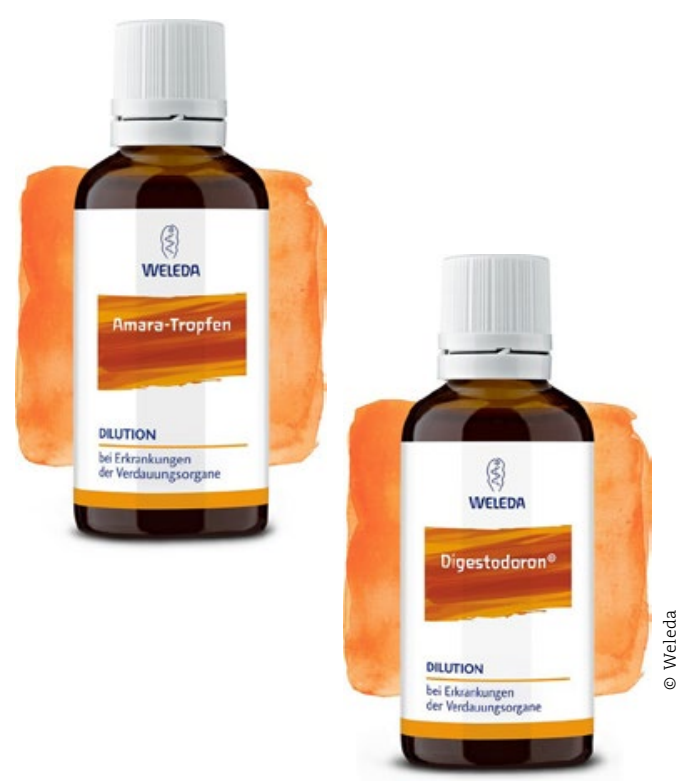

